\title{
Risk of postoperative complications among ulcerative colitis patients treated preoperatively with vedolizumab: a matched case-control study
}

\author{
Jeong Yeon Kim', Karen Zaghiyan², Amy Lightner ${ }^{3}$ and Phillip Fleshner ${ }^{2 *}$
}

\begin{abstract}
Background: Although biologic agents have revolutionized the medical management of severe ulcerative colitis $(\mathrm{UC})$, there is considerable controversy regarding adverse effects of vedolizumab on surgical outcomes. We evaluated 30-day postoperative morbidity in UC patients undergoing abdominal colectomy (AC) treated with vedolizumab before surgery.

Methods: From 2007 to 2017, 285 patients were enrolled in prospectively maintained database evaluating the role of clinical, serologic markers with clinical phenotypes in UC. The patients treated with vedolizumab within 12 weeks of $\mathrm{AC}$ was queried, then matched 1:3:3 into 3 preoperative treatment groups based on age, gender and surgical treatment of UC; ileal pouch-anal anastomosis (IPAA) with ileostomy vs total colectomy with end stoma: a) vedolizumab ( $n=25)$; b) anti-tumor necrosis factor (anti-TNF) $(n=74)$; and c) no biologics $(n=54)$. Thirty-day postoperative complications among patient groups were compared.

Results: The 3 patient groups were well-matched in other characteristics including disease duration, disease extent, medication history and preoperative serological data. There were no significant differences in the overall incidence of postoperative complications among patients treated preoperatively with vedolizumab, anti-TNFs, or no biologics (44\% vs. $45 \%$ vs. $37 \%$; $p=0.67$ ). Although there was no significant difference between patient cohorts in infectious complications $(p=0.20)$, postoperative ileus (POI) was significantly more common among the vedolizumab group $(n=$ $9 ; 36 \%)$ compared to anti-TNF $(n=12 ; 16 \%)$ or no biologics $(n=5 ; 9 \%)(p=0.01)$. Multivariable analysis showed that vedolizumab treatment prior to surgery was an independent risk factor for POI (OR: 5.16, 95\% Cl; 1.71-15.52; $p=.004$ ).
\end{abstract}

Conclusion: Although preoperative vedolizumab exposure did not influence the rate of overall 30-day postoperative complications, vedolizumab tends to increase incidence of POI.

Keywords: Ulcerative colitis, Vedolizumab, Postoperative complications

\section{Background}

By targeting various host immune molecules such as tumor necrosis factor (TNF), interleukins and adhesion molecules present on the surfaces of lymphocytes, biologics agents have revolutionized the medical management of inflammatory bowel disease (IBD). Despite these improvements, the need for surgical intervention in IBD

\footnotetext{
* Correspondence: Phillip.Fleshner@cshs.org

${ }^{2}$ Division of Colorectal Surgery, Cedars-Sinai Medical Center, 7 Beverly Blvd. Suite 101, Los Angeles, California 90048, USA

Full list of author information is available at the end of the article
}

remains high $[1,2]$, predisposing many patients to surgical intervention during exposure to biologic therapy.

Vedolizumab is a gut specific humanized monoclonal antibody which selectively binds to the $\alpha 4 \beta 7$ integrin, thereby blocking its interaction with mucosal addressin cell adhesion molecule-1 (MAdCAM-1). This action inhibits the migration of lymphocytes into the gastrointestinal lymph tissue and arrests the chronic inflammatory state of both ulcerative colitis (UC) and Crohn's disease (CD). This mechanism of action is a potential concern

(C) The Author(s). 2020 Open Access This article is distributed under the terms of the Creative Commons Attribution 4.0 International License (http://creativecommons.org/licenses/by/4.0/), which permits unrestricted use, distribution, and reproduction in any medium, provided you give appropriate credit to the original author(s) and the source, provide a link to the Creative Commons license, and indicate if changes were made. The Creative Commons Public Domain Dedication waiver (http://creativecommons.org/publicdomain/zero/1.0/) applies to the data made available in this article, unless otherwise stated. 
for surgeons as leukocyte migration to the intestinal mucosa may be vital for bowel inflammation [3-5].

The literature regarding potential effects of vedolizumab on surgical outcomes in IBD is conflicting, with some studies suggesting no effect [6-8] and others showing significant associations with surgical site infection [9-11]. These inconsistent findings may be attributed to several factors including retrospective study design, single institution experiences, variable duration of biologic therapies and time periods between the last biologic dose and surgery, heterogeneous patient populations and variable combinations of $C D$ and $U C$ [12]. In an effort to address some of these study concerns, we performed a matched casecontrol study of postoperative morbidity in medically refractory UC patients treated with vedolizumab before surgery. We hypothesized that postoperative complications would be comparable across vedolizumab treated, antiTNF treated and no biologic patient groups.

\section{Methods}

\section{Study population}

A prospectively maintained database from single tertiary hospital, evaluating the role of clinical, serologic and genetic markers with clinical phenotypes in IBD was queried for data on affected individuals with medically refractory UC undergoing first abdominal major surgery between January 2007 and June 2017. Patients requiring surgery for chronic disease with cancer, $\mathrm{CD}$, indeterminate colitis (IC), or those treated with ustekinumab prior to surgery were excluded. Those individuals with documented preoperative exposure to more than three times of vedolizumab within 12 weeks prior to surgery were selected and then matched 3:3:1 into 3 preoperative treatment groups (no biologics, anti-TNF treated, vedolizumab treated) based on age, gender and surgical procedure (abdominal colectomy with Brooke ileostomy or abdominal colectomy with ileal pouch-anal anastomosis (IPAA) with loop ileostomy). Approval for all research-related activities was obtained from the Institutional Review Board of the CedarsSinai Medical Center (\#33934).

\section{Assessment of clinical characteristics and complications}

Demographic information and characteristics of the disease and its treatment were tabulated. Patient factors included gender, age at surgery, body mass index (BMI), preoperative weight loss, smoking history, disease duration, disease extent, disease activity, medication history and number of stages to complete an IPAA. Preoperative weight loss was defined as greater than $10 \%$ loss of total body weight observed within 3 months of surgery. Disease duration was defined as the time interval between the diagnosis of UC and surgery. Smoking was defined as patients who smoked at the time of surgery or who had quit smoking before colectomy. We descripted disease extent, disease severity based on Montreal classification [13]. Anatomical extent of the disease was postoperatively categorized as left-sided colitis(E2) or pancolitis(E3). Disease severity was preoperatively categorized as moderate UC or severe UC. Disease activity was divided into two groups; acute vs chronic. Acute disease was defined as an acute condition needing emergency operation such as perforation or megacolon. Chronic activity was defined as a chronic disease condition needing elective surgery. Medication history included ever use of oral or parenteral corticosteroids or 6-mercaptopurine (or azathioprine) /methotrexate (6-MP / MTX) prior to surgery. Preoperative lab values (white blood cell count, platelet count and albumin) within 30 days of surgery were tabulated as surrogates of the patient's preoperative surgical risk. We followed guideline for peri, post-operative care by Enhanced Recovery After surgery (ERAS) Society Recommendation [14].

Postoperative complications were recorded within 30 days of the index operation. The occurrence of postoperative complications (infection, ileus and other sequelae) were identified from the medical files of all patients. All patients were systematically evaluated by the surgeon 7 , 30 days after surgery in outpatient's clinic. The complications were categorized as infection, postoperative ileus (POI), other morbidity and readmission. Infectious complications included surgical site infections (wound infection, abdominal/pelvic abscess), urinary tract infection and pneumonia. All patients were offered oral intake on postoperative day 1 . POI was defined clinically as nausea, vomiting, or abdominal distention requiring regression or cessation of diet, placement of nasogastric tube, or intravenous nutrition. The Grade I-POI was defined as POI without a clear mechanical obstruction identified radiologically. Grade II-POI was diagnosed with similar symptoms to Grade I-POI with a definite transition zone seen on imaging or at surgery.

\section{Statistical analysis}

Summary statistics were represented by counts (percentage) or median (range), where appropriate. Categorical variables were compared using a Chi-square test. Comparisons between population medians were performed using a Kruskal Wallis test for nonnormally distributed variables and ANOVA test for normally distributed variables. Chi-square test was used to compare 30 -day postoperative complication among three groups (no biologics vs. anti-TNF vs. vedolizumab). Logistic regression model was used to further investigate the association between surgical outcomes and clinical factors. All statistical analyses were performed using SPSS for Windows, version 17.0 (SPSS Inc., Chicago, IL, USA). All reported $p$ values were two-sided, with statistical significance set a priori at $p<0.05$. 


\section{Results}

Over the 11-year period, 285 patients had an abdominal colectomy by one surgeon. Total cohort data was tabulated (Table 1). A total of 25 procedures were identified as meeting entry criteria with exposure to vedolizumab. We used 1:3 matching based on age, gender and number of stages of patients treated with vedolizumab, of 77 patients with non-biologics, only 54 patients were eligible for matching condition. Seventy-four controls unexposed to vedolizumab yet who received anti-TNF therapy were matched 1:3. Anti-TNF agents used included infliximab $(n=48)$, adalimumab $(n=26)$. Although there were no significant statistical differences in clinical characteristics between the three groups, age was relatively older in non-biologics ( 37 vs 32 vs $31, p=0.13$ ), and previous medication of 6-MP or methotrexate rate was relatively less in the non-biologic group than the other two groups ( $45 \%$ vs $84 \%$ vs $80 \%, p=0.001$ ). As expected from strict case-control matching, baseline clinical characteristics were comparable between study groups. (Table 2).

Postoperative outcomes are shown in Table 3. Complications occurred in 64 patients $(42 \%)$. Infection $(n=11$; $20 \%)$ and postoperative ileus $(n=21 ; 13.7 \%)$ were the most common complications. Other morbidity included small bowel obstruction (SBO) $(n=7)$, dehydration $(n=4)$, and bleeding, Clostridium difficile enteritis, unexplained tachycardia, urinary retention, pancreatitis, deep vein thrombosis, stoma pain and rectal stump leak (all $n=1$ ). No patient required reoperation in the immediate postoperative period. The overall incidence of postoperative complications was not significantly different among patients treated preoperatively with vedolizumab, anti-TNFs, or no biologic $(p=0.67)$. Although univariate analysis showed no significant difference between patient cohorts in infectious complications, Grade I-POI was significantly more common among patients treated with vedolizumab compared to patients treated with anti-TNF or no biologics $(p=0.01)$. Grade IIPOI showed no significant difference between patients cohots $(p=0.89)$. Length of postoperative stay and 30-day readmission rate were not significantly different between patient three groups ( $p=0.17$ vs $p=0.36$ ) although patients with $\mathrm{POI}$ in vedolizumab group showed significantly longer length of postoperative stay compared to those without POI in vedolizumab group $((9(6-12))$ vs $5(3-5))$; $p=0.004))$.

Clinical factors associated with the development of Grade I-POI are shown in Table 4. Univariate analysis with total cohorts revealed that open surgery $(p=0.04)$, acute disease acti$\operatorname{vity}(p=0.04)$, vedolizumab use significantly $(p=0.04)$ increased the incidence of POI. Interestingly, 6MP or MTX treatment had the opposite effect, significantly reducing the incidence of postoperative ileus $(p=0.05)$. Multivariable analysis confirmed that vedolizumab treatment prior to surgery was an independent risk factor for Grade I-POI (OR: 4.86 95\% CI; 1.65-14.39; $p=0.004)$. Also, anti-TNF doubled the
Table 1 Patients' Characteristics

\begin{tabular}{|c|c|c|}
\hline & $N=285$ & $\%$ \\
\hline \multicolumn{3}{|l|}{ Gender } \\
\hline Male & 141 & 50.5 \\
\hline Female & 144 & 49.5 \\
\hline Age at surgery(Median) & $25(17-37)$ & \\
\hline BMI(kg/m2) (Median) & $22.6(19-27)$ & \\
\hline Disease duration (months) & $48(23.7-120)$ & \\
\hline \multicolumn{3}{|l|}{ Smoking } \\
\hline Never & 222 & 77.9 \\
\hline Prior & 56 & 19.6 \\
\hline Current & 7 & 2.5 \\
\hline \multicolumn{3}{|l|}{ Disease extent } \\
\hline E2 Left-side colitis & 35 & 12.3 \\
\hline E3 Pancolitis & 250 & 87.7 \\
\hline \multicolumn{3}{|l|}{ Disease Severity } \\
\hline S2 Moderate UC & 199 & 69.8 \\
\hline S3 Severe UC & 86 & 30.2 \\
\hline \multicolumn{3}{|l|}{ Disease activity } \\
\hline Acute & 18 & 93.7 \\
\hline chronic & 267 & 6.3 \\
\hline \multicolumn{3}{|l|}{ Medication history } \\
\hline Steroid & 90 & 31.6 \\
\hline 6-MP or MTX & 196 & 68.8 \\
\hline \multicolumn{3}{|l|}{ Immunosuppressant } \\
\hline Non-biologics & 77 & 27 \\
\hline Anti-TNF & 183 & 64.2 \\
\hline Anti-TNF adding Vedolizumab & 25 & 8.8 \\
\hline \multicolumn{3}{|l|}{ Operation type } \\
\hline Laparoscopy & 209 & 73.3 \\
\hline Open & 76 & 26.7 \\
\hline \multicolumn{3}{|l|}{ Operation performed } \\
\hline $\begin{array}{l}\text { Total abdominal colectomy } \\
\text { +end stoma }\end{array}$ & 92 & 32.3 \\
\hline Protectomy + IPAA with ileostomy & 193 & 67.7 \\
\hline \multicolumn{3}{|l|}{ Preoperative labs } \\
\hline Leukocyte( $\times 10^{3} /$ uL) (Median) & $9.4(6.6-12.5)$ & \\
\hline Platelet(X103/uL) (Median) & $350(274-475)$ & \\
\hline Albumin(g/dl) (Median) & $3.7(3.3-4.0)$ & \\
\hline
\end{tabular}

All values expressed as median (range) or $n$ (\%)

$B M I$ body mass index, 6-MP 6-mercaptopurine, MTX methotrexate, IPAA ileal pouch-anal anastomosis, TNF tumor necrosis factor

risk of Grade I-POI in multivariate analysis (OR: 2.45 95\% CI;1.51-14.70; $p=0.01$ ).

\section{Discussion}

The literature regarding the effect on vedolizumab on adverse postoperative outcomes in IBD patients remains 
Table 2 Clinical Features of the Three Study Cohorts with Case Matched

\begin{tabular}{|c|c|c|c|c|}
\hline & $\begin{array}{l}\text { None } \\
(n=54)\end{array}$ & $\begin{array}{l}\text { Anti-TNF } \\
(n=74)\end{array}$ & $\begin{array}{l}\text { Vedolizumab } \\
(n=25)\end{array}$ & $p$ \\
\hline Gender (M/F) & $29: 25$ & $35: 39$ & $13: 12$ & 0.76 \\
\hline Age at surgery (years) & $35(23-49)$ & $30(21-45)$ & $31(22-47)$ & 0.31 \\
\hline $\mathrm{BMI}\left(\mathrm{kg} / \mathrm{m}^{2}\right)$ & 23.3(19-28) & $22.7(19-26)$ & 21.1(19-26) & 0.15 \\
\hline Preoperative weight loss (> $10 \mathrm{lbs})^{a}$ & $17(35)$ & $23(37)$ & $10(43)$ & 0.79 \\
\hline Missing & $6(11)$ & $11(15)$ & 2(8) & 0.63 \\
\hline Disease duration (mos) & $61(24-152)$ & $53(20-195)$ & $60(24-148)$ & 0.46 \\
\hline Smoking & & & & 0.74 \\
\hline Never & $43(80)$ & $59(80)$ & $21(84)$ & \\
\hline Prior & $8(15)$ & $13(17)$ & $4(16)$ & \\
\hline Current & $3(5)$ & $2(3)$ & 0 & \\
\hline Disease extent & & & & 0.89 \\
\hline E2 Left-sided colitis & $7(13)$ & $9(12)$ & $4(16)$ & \\
\hline E3 Pancolitis & $47(87)$ & $65(88)$ & $21(84)$ & \\
\hline Disease activity & & & & 0.714 \\
\hline Acute & $3(5.6)$ & $2(2.7)$ & $1(4.0)$ & \\
\hline Chronic & $51(94.4)$ & $73(2.7)$ & $24(4.0)$ & \\
\hline \multicolumn{5}{|l|}{ Medication history } \\
\hline Steroids & $34(68)$ & $48(68)$ & $18(72)$ & 0.92 \\
\hline 6-MP or MTX & $24(45)$ & $62(84)$ & $20(80)$ & 0.001 \\
\hline \multicolumn{5}{|l|}{ Operation type } \\
\hline open & $16(30)$ & $19(26)$ & $6(16)$ & 0.83 \\
\hline laparoscopy & $38(70)$ & $55(74)$ & $19(76)$ & \\
\hline \multicolumn{5}{|l|}{ Operation performed } \\
\hline $\begin{array}{l}\text { Total abdominal colectomy } \\
\text { +end stoma }\end{array}$ & $15(28)$ & $15(20)$ & $5(20)$ & 0.57 \\
\hline Protectomy + IPAA with ileostomy & $39(72)$ & $59(80)$ & $20(80)$ & \\
\hline lleostomy repair & $46(85)$ & $60(81)$ & $19(76)$ & 0.61 \\
\hline \multicolumn{5}{|l|}{ Preoperative labs } \\
\hline Leukocyte ( $\times 10^{3} /$ uL) & $8.9(6.5-12.4)$ & $9(6.4-13)$ & $9.8(6.9-12)$ & 0.79 \\
\hline Platelet ( $\left.\times 10^{3} / \mathrm{uL}\right)$ & $360(281-475)$ & $350(280-459)$ & $340(274-487)$ & \\
\hline Albumin $(g / d L)$ & $3.6(3.3-4.0)$ & $3.6(3.2-4.1)$ & $3.9(3.6-4.2)$ & $\begin{array}{l}0.87 \\
0.25\end{array}$ \\
\hline
\end{tabular}

All values expressed as median (range) or $\mathrm{n}(\%)$

$B M I$ body mass index, 6-MP 6-mercaptopurine, MTX methotrexate, IPAA ileal pouch-anal anastomosis, TNF tumor necrosis factor

${ }^{a} 19$ cases with data missing

controversial. We therefore sought to understand outcomes following abdominal surgery for UC in those patients treated preoperatively with vedolizumab as compared to anti-TNF or no biologic therapy. We found the preoperative exposure to vedolizumab did not increase the rates of overall postoperative complications, infectious complications, or 30-day readmission compared to patients using anti-TNFs or those with no biologic drug exposure. However, we did find a novel association of preoperative vedolizumab exposure and the development of POI.
As with any immunosuppressive drug, surgeons have expressed concern regarding the potential for serious postoperative complications with the preoperative use of biologic drugs. There is considerable controversy regarding the potential adverse effects of anti-TNFs on surgical outcomes with studies showing conflicting results [12]. Factors responsible for this surgical controversy, such as retrospective study design, inclusion of both $\mathrm{CD}$ and $\mathrm{UC}$ patients, varying surgical procedures, and diverse patient populations have also accounted for reports showing inconsistent effects of vedolizumab on surgical outcomes. 
Table 3 Surgical Outcomes of the Three Study Cohorts with Case-Matched

\begin{tabular}{|c|c|c|c|c|}
\hline & $\begin{array}{l}\text { None } \\
(n=54)\end{array}$ & $\begin{array}{l}\text { Anti-TNF } \\
(n=74)\end{array}$ & $\begin{array}{l}\text { Vedolizumab } \\
(n=25)\end{array}$ & $p$ \\
\hline Overall morbidity & $20(37)$ & $33(45)$ & $11(44)$ & 0.67 \\
\hline Infectious complications & $11(20)$ & $8(11)$ & $2(8)$ & 0.20 \\
\hline Pelvic abscess & 0 & $2(3)$ & $1(4)$ & \\
\hline Wound infection & $9(17)$ & $5(8)$ & $1(4)$ & \\
\hline Urinary tract & $1(2)$ & 0 & 0 & \\
\hline Pneumonia & $1(2)$ & 0 & 0 & \\
\hline \multicolumn{5}{|l|}{ Post-operative Ileus } \\
\hline Grade I & $5(9)$ & $12(16)$ & $9(36)$ & 0.01 \\
\hline Grade II & $3(6)$ & $4(5)$ & $2(8)$ & 0.89 \\
\hline Other morbidity & $4(8)$ & $13(18)$ & $1(4)$ & 0.14 \\
\hline Postoperative stay (d) & $6(5-8)$ & $6(5-8)$ & $5(3-9)$ & 0.17 \\
\hline 30-day readmission & $7(13)$ & $11(15)$ & $1(4)$ & 0.36 \\
\hline
\end{tabular}

All values expressed as median (range) or $\mathrm{n}(\%)$ TNF tumor necrosis factor

To address these issues, our study prospectively collected surgical outcomes in only UC patients undergoing one of two procedures. We further minimized study bias by case matching vedolizumab exposed, anti-TNF exposed and no biologic exposed patients. These methods resulted in patient cohorts well matched for clinical features, serum laboratory values, and operative procedures.

The current study adds to the 3 prior reports of vedolizumab in UC $[8,15,16]$. While one study showed a significant association with surgical site infection, our study concurs with the other two studies showing no deleterious effect of vedolizumab on overall complications and specifically infectious complications. In our whole cohort, patients with non-biologics tend to show high incidence of infection, but it would be related with high steroid use or higher incidence of IPAA. Except the infection complication rate, the total cohort showed similar tendency with 1:3 matching case control data of postoperative complication such as POI, postoperative stay or 30-day readmission rate.

A novel finding in our study was the significant association of preoperative vedolizumab use and the development of POI. While we acknowledge the lack of a consistent definition of POI in the literature [17], our definition of POI was the same across all 3 patient groups. Although POI is significantly higher in Vedolizumab group, postoperative stay did not show significant different between the 3 patient groups. Our data is longterm collected data, with recent treatment being early ambulation, early feeding to reduce ileus, and the length of hospital day being much shorter than before. Although the median values of the three groups do not seem to be statistically different, it was significantly longer in vedolizumab treated patients who developed POI compared with vedolizumab treated patients not developed POI (8.7 days vs 4.7 days). In addition, despite the numerous efforts to reduce POI with strictly followed ERAS protocol, it is more noteworthy that the incidence of ileus was highly developed in patients with the recently used medication, Vedolizumab. As we know, the $\alpha 4 \beta 7$ is focused on blocking leukocytes targeting the mucosa of the bowel while the anastomosis mainly heals within the serosa. So, we found the reason, not with wound healing but with bowel motility, for the effect on the master cell of $\alpha 4 \beta 7$. It is plausible but unproven that vedolizumab may influence mast cell stability with the subsequent development of POI. Mast cells are known to be important players in the intestinal inflammation that mediates dysfunction of gastrointestinal motility, and recent experimental studies have shown that mast cells have a high level of $\alpha 4 b 7$ integrin on their surface and strong contact of MAdcam-1 on other surfaces [18-20].

Another novel finding was the protective effect of 6-MP or MTX on the development of POI. All previous reports investigating the association of these immunomodulatory agents with increased postoperative complication rates in patients with IBD have been retrospective, with the two largest series focused on infectious complications without even mentioning POI in the analysis [21, 22]. While animal studies have demonstrated the prokinetic effects of MTX [23], we await future studies on the mechanism of immunosuppressive agents on gut motility in IBD to validate our findings with a larger number of patients.

The most glaring limitation of our study is the small number of vedolizumab treated patients with pre-exposure with anti-TNF, reflecting the relatively short period the drug has been approved for UC [24] combined with our center's concern regarding the clinical utility of the drug's slow onset of action in these severe UC patients. And, this study included the patients who have been treated since 2007 although we attempted to lower the bias by casematching. This was due to the need for comparison with the non-biologic group, but it is possible that the surgical and medical therapies have changed between 2007 and 2014. We also recognize this model would not be suitable for all surgeons or all hospital, since this study was done in tertiary hospital by single surgeon. Difference hospital can have a significant difference in preoperative or postoperative treatment. Nevertheless, as our data show, Vedolizumab group increased the incidence of Grade I POI by four-fold compared with the non-biologic group and by 2 two-fold compared with the anti-TNF group, although all patients were treated with the same pre/post-operative management following ERAS protocol (A clear liquid diet continued $<2 \mathrm{~h}$ before 
Table 4 Regression Analysis for Grade I- Postoperative Grade I lleus with total cohort

\begin{tabular}{|c|c|c|c|c|c|c|}
\hline & Univa & & & Multi & lysis & \\
\hline & $\mathrm{OR}$ & OR 95\% Cl & $p$ & $\mathrm{OR}$ & OR 95\%Cl & $\mathrm{p}$ \\
\hline Gender (M/F) & 1.77 & $0.97-3.1$ & 0.06 & & & \\
\hline Age at surgery(years) & 1.01 & $0.94-1.02$ & 0.94 & & & \\
\hline BMI $\left(\mathrm{kg} / \mathrm{m}^{2}\right)$ & 0.11 & $0.41-2.7$ & 0.55 & & & \\
\hline $\begin{array}{l}\text { Preoperative wt loss } \\
(>10 \mathrm{lb})^{\mathrm{a}}\end{array}$ & 1.05 & $0.41-2.7$ & 0.92 & & & \\
\hline Disease duration (mos) & 0.99 & $0.99-1.02$ & 0.59 & & & \\
\hline Smoking & & & & & & \\
\hline Never & & & & & & \\
\hline Prior & 0.97 & $0.47-2.0$ & 0.97 & & & \\
\hline Current & 0.67 & $0.79-5.7$ & 0.72 & & & \\
\hline Disease extent & & & & & & \\
\hline E2 Left-sided colitis & & & & & & \\
\hline E3 Pancolitis & 1.45 & $066-3.40$ & 0.34 & & & \\
\hline Disease severity & & & & & & \\
\hline S2 Moderate UC & & & & & & \\
\hline S3 Severe UC & 1.12 & $0.60-2.12$ & 0.72 & & & \\
\hline Disease activity & & & & & & \\
\hline Chronic & & & & & & \\
\hline Acute & 2.83 & $1.05-7.67$ & 0.04 & 3.09 & $1.11-8.61$ & 0.03 \\
\hline Medication history & & & & & & \\
\hline Steroids & 0.92 & $0.59-1.98$ & 0.92 & & & \\
\hline 6-MP or MTX & 0.53 & $0.29-0.97$ & 0.04 & 0.56 & $0.28-1.07$ & 0.08 \\
\hline IPAA stages & & & & & & \\
\hline $\begin{array}{l}\text { Total abdominal colectomy } \\
\text { +end stoma }\end{array}$ & & & & & & \\
\hline Protectomy + IPAA with ileostomy & 1.24 & $0.65-2.40$ & 0.51 & & & \\
\hline Operation type & & & & & & \\
\hline Open & & & & & & \\
\hline laparoscopy & 0.53 & $0.28-0.98$ & 0.04 & 0.54 & $0.27-1.06$ & 0.07 \\
\hline Preoperative labs & & & & & & \\
\hline Leukocyte (×103/uL) & 1.00 & $1.00-1.00$ & 0.45 & & & \\
\hline Platelet $\left(\times 10^{3} / \mathrm{uL}\right)$ & 1.01 & $0.99-1.00$ & 0.34 & & & \\
\hline Albumin $(g / d L)$ & 0.82 & $0.40-1.65$ & 0.58 & & & \\
\hline Biologic agent & & & & & & \\
\hline None & & & & & & \\
\hline Anti-TNF & 1.76 & $0.83-3.73$ & 0.14 & 2.45 & $1.08-5.59$ & 0.03 \\
\hline Vedolizumab & 3.15 & $1.08-9.2$ & 0.04 & 4.71 & $1.51-14.70$ & 0.01 \\
\hline
\end{tabular}

OR odds ratio, $C l$ confidence interval, $B M I$ body mass index, 6-MP 6-mercaptopurine, MTX methotrexate, CSA cyclosporine A, IPAA ileal pouch-anal anastomosis, TNF tumor necrosis factor

general anesthesia; Mechanical bowel preparation plus oral antibiotic bowel preparation was done; Opioid-sparing pain control; Anti-emetic prophylaxis were added; Maintenance infusion of crystalloids should be tailored to avoid excess fluid administration; Nasogastric tube were avoided; Early and progressive patient mobilization; Early feeding $<24 \mathrm{~h}$ ). Hence, we acknowledge that further validation of our findings with a larger number of patients is necessary. Nonetheless, our findings have shed further light into the UC patients who needed surgery prior to exposure of vedolizumab. 


\section{Conclusions}

Vedolizumab treated UC patients appear to be at risk for the development of POI. We encourage investigators to validate this finding in their own patient cohorts. In the interim, strategies for management of POI such as minimally invasive surgical technique, avoidance of a routine postoperative nasogastric tube, and use of opioid-sparing analgesia combined with early mobilization and oral feeding should be emphasized. There may also be a role for prokinetic agents such as alvimopan or methylnaltrexone [25-28].

\section{Abbreviations}

6-MP: 6-mercaptopurine; AC: Abdominal colectomy; anti-TNF: Anti-tumor necrosis factor; BMI: Body mass index; CD: Crohn's disease; ERAS: Enhanced Recovery After surgery; IBD: Inflammatory bowel disease; IC: Indeterminate colitis; IPAA: Ileal pouch-anal anastomosis; MAdCAM-1: Mucosal addressin cell adhesion molecule-1; MTX: Methotrexate; POI: Postoperative ileus; SBO: Small bowel obstruction; UC: Ulcerative colitis

\section{Acknowledgements}

We have presented this work at the Society for Surgery of the Alimentary Tract 59th Annual Meeting (2018).

\section{Authors' contributions}

Data collection, analysis and writing were done by JYK. Data analysis was done by KZ and reviewed by AL. Study design and reviewed by PF. All authors have read and approved this manuscript.

\section{Funding}

There is no funding.

\section{Availability of data and materials} Not applicable.

\section{Ethics approval and consent to participate}

The surgery was a standard procedure, and the patient was well informed of the operation risk. The patient was informed that treatment results are included in study analysis while patient's personal information will not be shared. Study was approved by the Cedars-Sinai Medical Center IRB (\#3358).

\section{Consent for publication}

not applicable

\section{Competing interests}

The authors declare that they have no competing interests.

\section{Author details}

'Department of Surgery, Hallym University College of Medicine, Dongtan, South Korea. ${ }^{2}$ Division of Colorectal Surgery, Cedars-Sinai Medical Center, 7 Beverly Blvd., Suite 101, Los Angeles, California 90048, USA. ${ }^{3}$ Department of Colon and Rectal Surgery, Cleveland Clinic Foundation, Cleveland, Ohio, USA.

Received: 16 July 2019 Accepted: 14 February 2020

Published online: 05 March 2020

\section{References}

1. Jones DW, Finlayson SR. Trends in surgery for Crohn's disease in the era of infliximab. Ann Surg. 2010;252(2):307-12.

2. Danese S, Fiocchi C. Ulcerative colitis. N Engl J Med. 2011;365(18):1713-25.

3. Frostbert E, Strom P, Gerke QN. Infliximab's influence on anastomotic strength and degree of inflammation in intestinal surgery in a rabbit model. BMC Surg. 2014;14:23.

4. Thompson SK, Chang EY, Jobe BA. Clinical review: healing in gastrointestinal anastomoses, part I. Microsurgery. 2006;26(3):131-6.

5. Teller $\mathrm{P}$, White TK. The physiology of wound healing: injury through maturation. Surg Clin North Am. 2009;89(3):599-610.
6. Koh S, Zaghiyan K, Fleshner P. Safety and efficacy of the perioperative use of vedolizumab in medically refractory IBD patients. Does "gut-specificity" impact surgical morbidity? Dis Colon Rectum. 2016;59(5):E33.

7. Ferrante M, Schils N, de Buck van Overstraeten A, Schils N, Moens A, Van Assche $G$, Wolthuis A, Vermeire S, D'Hoore A. Perioperative use of vedolizumab is not associated with short-term postoperative infectious complications in patients with ulcerative colitis undergoing (procto) colectomy with ileal pouch-anal anastomosis. Gastroenterology. 2017;152(5 Suppl 1):S581-2.

8. Yamada A, Komaki Y, Patel N, Patel N, Komaki F, Aelvoet AS, Tran AL, Pekow J, Dalal S, Cohen RD, Cannon L, Umanskil K, Smith R, Hurst R, Hyman N, Rubin DT, Sakuraba A. Risk of postoperative complications among inflammatory bowel disease patients treated preoperatively with vedolizumab. Am J Gastroenterol. 2017;112:1423-9.

9. Lightner AL, Raffals LE, Mathis KL, Cima RR, Tse CS, Pemberton JH, Dozois EJ, Loftus EV. Postoperative outcomes in vedolizumab-treated patients undergoing abdominal operations for inflammatory bowel disease. J Crohns Colitis. 2017;11:185-90.

10. Stringfield S, Parry L, Sandborn WJ, Ramamoorthy S, Eisenstein S. Patients on vedolizumab have a high rate of postoperative complications. Dis Colon Rectum. 2016;69(5):E33.

11. Lightner AL, Mathis KL, Tse CS, Pemberton JH, Shen B, Kochlar G, Singh A, Dulai PS, Eisenstein S, Sandborn WJ, Parry L, Stringfiled S, Hudesman D, Remzi F, Loftus EV Jr. Postoperative outcomes in vedolizumab treated patients undergoing major abdominal operations for inflammatory bowel disease: retrospective multicenter cohort study. Inflamm Bowel Dis. 2018;24:871-6.

12. Zaghiyan K, McGovern D, Fleshner P. Should biologic agents be stopped before surgery for inflammatory bowel disease? Expert Rev Gastroenterol Hepatol. 2015;9(3):269-72.

13. Satsangi J, Silverberg MS, Vermeire S, Colombel JF. The Montreal classification of inflammatory bowel disease: controversies, consensus, and implications. Gut. 2006;55(6):849-53.

14. Kunitake $H$. Enhanced recovery after surgery for colorectal surgery. Clin Colon Rectal Surg. 2019:32(2):93-4.

15. Lightner AL, McKenna NP, Moncrief S, Pemberton JH, Raffals LE, Mathis KL. Surgical outcomes in Vedolizumab-treated patients with ulcerative colitis. Inflamm Bowel Dis. 2017;23(12):2197-201.

16. Ferrante M, de Buck van Overstraeten A, Schils N, Moens A, Van Assche G, Wolthuis A, Vermeire S, D'Hoore A. Perioperative use of Vedolizumab is not associated with postoperative infectious complications in patients with ulcerative colitis undergoing colectomy. J Crohns Colitis. 2017;11(11):1353-61.

17. Grass F, Slieker J, Jurt J, Kummer A, Solà J, Hahnloser D, Demartines N, Hübner M. Postoperative ileus in an enhanced recovery pathway-a retrospective cohort study. Int J Color Dis. 2017;32(5):675-81.

18. De Giorgio R, Barbara G. Evidence for mast cell involvement in human postoperative ileus: a novel link. Gut. 2008;57(1):5-7.

19. The FO, Bennink RJ, Ankum WM, Buist MR, Busch OR, Gouma DJ, van der Heide S, van den Wijngaard RM, de Jonge WJ, Boeckxstaens GE. Intestinal handling-induced mast cell activation and inflammation in human postoperative ileus. Gut. 2008;57(1):33-40.

20. The FO, Buist MR, Lei A, Bennink RJ, Hofland J, van den Wijngaard RM, de Jonge WJ, Boeckxstaens GE. The role of mast cell stabilization in treatment of postoperative ileus: a pilot study. Am J Gastroenterol. 2009:104(9):2257-66.

21. Aberra FN, Lewis JD, Hass D, Rombeau JL, Osborne B, Lichtenstein GR. Corticosteroids and immunomodulators: postoperative infectious complication risk in inflammatory bowel disease patients. Gastroenterology. 2003;125(2):320-7.

22. Afzali A, Park CJ, Zhu K, Hu JK, Sharma P, Sinanan MN, Lee SD. Preoperative use of methotrexate and the risk of early postoperative complications in patients with inflammatory bowel disease. Inflamm Bowel Dis. 2016;22(8):1887-95.

23. Williams AS, Topley N, Dojcinov S, Richards PJ, Williams BD. Amelioration of rat antigen-induced arthritis by liposomally conjugated methotrexate is accompanied by down-regulation of cytokine mRNA expression. Rheumatology (Oxford). 2001;40(4):375-83.

24. Aggarwal A, Sabol T, Vaziri H. Update on the use of biologic therapy in ulcerative colitis. Curr Treat Options Gastroenterol. 2017;15(1):155-67.

25. Frost EA. Preventing paralytic ileus: can the anesthesiologist help. Middle East J Anaesthesiol. 2009;20(2):159-65.

26. Abraham NS, Young JM, Solomon MJ. Meta-analysis of short-term outcomes after laparoscopic resection for colorectal cancer. Br J Surg. 2004;91(9):1111-24.

27. Lobo DN, Bostock KA, Neal KR, Perkins AC, Rowlands BJ, Allison SP. Effect of salt and water balance on recovery of gastrointestinal 
function after elective colonic resection: a randomised controlled trial. Lancet. 2002;359(9320):1812-8.

28. Delaney CP, Zutshi M, Senagore AJ, Remzi FH, Hammel J, Fazio WW.

Prospective, randomized, controlled trial between a pathway of controlled

rehabilitation with early ambulation and diet and traditional postoperative care after laparotomy and intestinal resection. Dis Colon Rectum. 2003:46(7):851-9.

\section{Publisher's Note}

Springer Nature remains neutral with regard to jurisdictional claims in published maps and institutional affiliations.

Ready to submit your research? Choose BMC and benefit from:

- fast, convenient online submission

- thorough peer review by experienced researchers in your field

- rapid publication on acceptance

- support for research data, including large and complex data types

- gold Open Access which fosters wider collaboration and increased citations

- maximum visibility for your research: over $100 \mathrm{M}$ website views per year

At $B M C$, research is always in progress.

Learn more biomedcentral.com/submissions 